\title{
New insights into the genetics of addiction
}

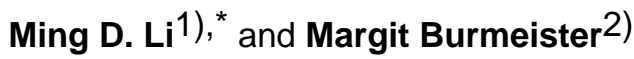 \\ 1)Department of Psychiatry and Neurobehavioral Sciences, University of Virginia, 1670 Discovery \\ Drive, Suite 110, Charlottesville, Virginia 22911, USA \\ 2)Molecular \& Behavioral Neuroscience Institute, Departments of Psychiatry and Human Genetics, \\ University of Michigan, M4140 SPH II, 109 South Observatory Street, Ann Arbor, Michigan, 48019, \\ USA
}

\begin{abstract}
Drug addiction is a common brain disorder that is extremely costly to the individual and to society. Genetics contributes significantly to vulnerability to this disorder, but identification of susceptibility genes has been slow. Recent genome-wide linkage and association studies have implicated several regions and genes in addiction to various substances, including alcohol and, more recently, tobacco. Current efforts aim not only to replicate these findings in independent samples but also to determine the functional mechanisms of these genes and variants.
\end{abstract}

Addictions are chronic, often relapsing disorders characterized by obsession, compulsion, or physical or psychological dependence. The World Health Organization estimates that there are 2 billion alcohol users, 1.3 billion tobacco users, and 185 million illicit-drug users worldwide. Twin and family studies provide strong evidence that addictions involve the interplay of genetic and environmental factors. ${ }^{1-5}$ Greater knowledge of the genetics underlying addiction therefore is crucial for the development of more effective interventions. For example, after attempting to quit, smokers of European ancestry with the CYP2B $6 * 6$ genotype are more likely to relapse than those with other genotypes when on placebo but can be helped by bupropion treatment. ${ }^{6}$

In recent years, significant progress has been made in identifying susceptibility genes for addictions. Given that most of this progress primarily on a specific substance has been covered in other reviews,${ }^{1-5,7}$ we focus here on the most recent advances made through the use of linkage and association approaches, especially with genome-wide association study (GWAS); our goal is to provide an updated summary of identified susceptibility loci/genes for multiple substances. Regions on human chromosomes 4, 5, 9-11, and 17 are more likely to harbor susceptibility genes for multiple substances. Among the susceptibility genes for addiction identified from candidate gene-based or GWAS approaches, we limit our focus to representative genes that encode aldehyde dehydrogenase $(A D H)$, nicotinic acetylcholine receptor (nAChR) subunits, $\mathrm{GABA}_{\mathrm{A}}$ (gamma-aminobutyric acid A) receptor subunit 2 (GABRA2), ankyrin repeat and kinase domain containing 1 (ANKK1), and neurexins, because of their influence on susceptibility to addiction to multiple substances, the strong statistical evidence to support their roles, or the importance of their biological functions in addiction. We first focus on evidence for the contribution of genetics to addiction, then on the recently identified loci/gene that confer susceptibility to multiple substances, and finally on the knowledge gained from engineered mice.

*Correspondence to: Ming D. Li, Ph.D. University of Virginia Department of Psychiatry and Neurobehavioral Sciences Section of Neurobiology 1670 Discovery Drive, Suite 110 Charlottesville, VA 22911 Tel: (434) 243-0566 Fax: (434) 973-7031

Ming_Li@virginia.edu. 


\section{Genetic contribution to addictions}

Epidemiological studies strongly suggest that genetic factors operate at all steps of addiction, including vulnerability to initiation, continued use, and propensity to become dependent (Box 1). Twin studies have been popular to investigate the relative contributions of genetic and environmental factors. In addition to estimating genetic liability, twin studies provide information about environmental contributions, including the availability of and exposure to a substance, and shared and unique environments. The genetic influence on addiction has proved to be substantial, and heritablities for most addictive disorders are moderate to high.

Numerous large twin studies for alcohol-related behaviors have consistently shown that heritability of alcohol abuse and dependence ranges from $50 \%$ to $70 \% .{ }^{8} \mathrm{~A}$ similarly high heritability also is seen across other alcohol-related behaviors, including heavy consumption and 'problem' drinking. ${ }^{8}$ Meta-analysis of the twin studies shows that both genes and environment are important in smoking-related behaviors, with an estimated mean heritability of 0.50 for smoking initiation and 0.59 for nicotine dependence (ND). ${ }^{4}$ Genetic factors have a larger role in initiation than in persistence in women, whereas the opposite is observed in men. 4,9

Fewer studies have examined genetic influences on illicit drug addiction. Heritability of the use/dependence on stimulants, sedatives, and heroin in males is $0.33,0.27$, and 0.54 , respectively. ${ }^{10}$ These values are similar to those seen in females, although such studies are rarer. ${ }^{11}$ Moreover, twin studies indicate a large overlap between the genetic predispositions to dependence and that to most classes of substances. For example, twin studies suggest that nicotine and alcohol dependencies share more than $60 \%$ of their genetic vulnerabilities. ${ }^{12}$

Finally, we point out that heritability is specific to the sample under study. Thus, the role of genetic influences may differ across samples, and heritability may be affected by many factors, such as sex, age, education, socioeconomic status, and cultural background.

\section{Identifying susceptibility loci for addiction}

Both LINKAGE and association mapping have identified susceptibility loci for addiction-related phenotypes, especially for alcohol dependence (AD) and ND. However, few putative genome linkages have been replicated in independent studies, probably because of GENETIC HETEROGENETT.

Despite these limitations, significant progress has been made, especially for AD and ND. Linkage studies have identified a locus on chromosome $4 \mathrm{q}$ near the $A D H$ gene cluster as a major locus for alcoholism in American Indians and Caucasians, ${ }^{13-15}$ in addition to the known $A D H 2$ and aldehyde dehydrogenase $2(A L D H 2)$ variants in Asians and Jewish Americans. ${ }^{16-}$ 18 The $A D H$ locus contains a cluster of seven genes, of which $A D H 2$ is the most important across populations, ${ }^{19}$ although functional variants in $A D H 4$ and $A D H 7$ might also be involved. $16,20,21$

One of the most successful examples of the postronal candidate Gene approach in addiction research has been the identification of $G A B R A 2$ as a susceptibility factor for alcoholism. Early linkage studies in Southwest American Indians ${ }^{13}$ implicated chromosome $4 \mathrm{p}$ near the GABRA2/BI cluster; these results were confirmed in some Caucasian studies, ${ }^{22}$ and became particularly convincing when linkage of alcohol-related phenotypes was combined with QUANTITATIVE TRAIT Locus (QTL) MAPPIng of electroencephalographic quantitative trait data. ${ }^{23}$ Initial association findings of $G A B R A 2^{24}$ in that linkage region were replicated in multiple studies, ${ }^{25-27}$ so that $G A B R A 2$ is now considered a confirmed risk locus for AD. 
Similarly, variants in $G A B B R 2$ (on chromosome 9q22), which encodes the $\mathrm{GABA}_{\mathrm{B}}$ receptor subunit 2, have been associated with ND. ${ }^{28}$ Linkage of chromosome 9 with smoking behavior has been reported in several independent studies, ${ }^{29-32}$ and GABBR2 contributes $28 \%-38 \%$ to this linkage signal. ${ }^{33}$ The involvement of GABA signaling across addictions has been confirmed in animal models (see below).

Although many linkage scans have been reported for addiction to a specific drug, only few have investigated the convergence of linkage peaks across drug addictions. Toward this objective, we searched for linkage peaks among multiple abused substances, according to the criteria proposed by Lander and Kruglyak. ${ }^{34}$ We found that regions on chromosomes 2-5, 7, 9-11, 13, 14, and 17 have independent evidence of "suggestive" or "significant" linkage, with regions on chromosomes $4,5,9,10,11$, and 17 receiving the strongest support for harboring susceptibility genes for addictions to multiple drugs (Figure 1).

Although many candidate genes have been investigated for associations with addiction, only a few findings have been replicated in independent studies for multiple addictions. Instead of giving a detailed review of these candidates individually, our discussion focuses on representative genes that have recently received much attention or are associated with addictions to multiple substances.

\section{Susceptibility genes for substance addiction}

In the past two years, the most significant findings in addiction genetics have been the involvement of a few $\mathrm{nAChR}$ subunit genes specifically in ND and more generally in substance abuse. As illustrated in Box 2, nicotine exerts its biological function by binding to nAChRs, which are composed of five subunits. There are $12 \mathrm{nAChR}$ subunit genes: nine alpha ( $\alpha 2-$ $\alpha 10)$ and three beta ( $\beta 2-\beta 4)$ subunits. Variants have been associated with dependence on nicotine, alcohol, and cocaine and with lung cancer susceptibility, as explained below.

\section{nAChR $\alpha 4$ subunit gene}

A significant association of variants in CHRNA4, which encodes the $\alpha 4$ subunit, with ND has been detected in three independent studies. The first study revealed significant protective effects of two SNPs against ND in Chinese men. ${ }^{35}$ A second study showed that four SNPs and нарцотүреS that consisted of these SNPs are significantly associated with ND in European and African Americans, but the effects differed as a function of ethnicity or sex. ${ }^{36} \mathrm{~A}$ third study reported that two SNPs are significantly associated with the subjective response to smoking. ${ }^{37}$ Although not all associations have been replicated, two SNPs (rs1044396 and rs2236196) are consistent in two of the three studies. Together, these studies provide evidence that variations in CHRNA4 influence ND.

\section{Association and interaction analysis of CHRNB2}

By contrast, no significant association of $C H R N B 2$, which encodes the $\beta 2$ subunit, with ND was reported in four independent studies (e.g., see ${ }^{35,36}$ ), except for a significant association of rs2072661 in the $3^{\prime}$-UTR of the gene with ability to quit smoking. ${ }^{38}$ However, epistatic analysis using a generalized multifactor dimensionaltT Reduction metrod ${ }^{39}$ revealed that $C H R N B 2$ has a significant effect on ND when analyzed with CHRNA4 together. ${ }^{40}$ The failure to detect significant association of $C H R N B 2$ with ND by itself may thus be attributable to the relatively small effect of CHRNB2 or strong dependency of CHRNB2 effects on specific CHRNA4 variants. More importantly, detection of significant interaction of CHRNB2 with CHRNA4 in humans is consistent with the formation of functional nAChRs with these two subunits. ${ }^{41,42}$ A moderate association of $C H R N B 2$ with early response to alcoholism has also been reported. 43 
Recent development of selective partial agonists of $\alpha 4 \beta 2 \mathrm{nAChRs}$ as effective smokingcessation agents further supports the role of $\alpha 4 \beta 2 \mathrm{nAChRs}$ in ND. For example, the partial $\alpha 4 \beta 2 \mathrm{nAChR}$ agonist vareniclinie was approved by the US Food and Drug Administration as an aid to smoking cessation. It produces significantly higher quit rates $(2-3 \times)$ than do other treatments. ${ }^{44}$ Vareniclinie can selectively decrease ethanol consumption and seeking in animals, implying it may be valuable also for the treatment of alcoholism. ${ }^{45}$

\section{Association of CHRNA5/A3/B4 with ND and lung cancer}

Three recent GWASs suggested a strong association between variants of $C H R N A 5 / A 3 / B 4$ (encoding subunits $\alpha 5, \alpha 3$, and $\beta 4$ ) at $15 \mathrm{q} 24$ and lung cancer. ${ }^{46-48}$ However, although one study revealed a significant association of a CHRNA3 SNP with ND, ${ }^{48}$ the other two studies suggested association of this and other variants with lung cancer independent of their association with smoking. ${ }^{46,47}$ Several other studies provide independent verification of the association between this gene cluster and $\mathrm{ND},{ }^{49-51}$ and suggest that power, precision of phenotyping, or severity may explain the apparent association with lung cancer rather than a direct, smoking-independent association. We feel that a biological link between variants in the CHRNA5/A3/B4 cluster and ND is more plausible than a direct effect of these variants on lung cancer.

\section{Association of CHRNA5/A3/B4 with alcohol and cocaine dependence}

Association of the CHRNA5/A3/B4 gene cluster with alcohol and cocaine addictions has been reported. Wang et al. ${ }^{52}$ identified a group of SNPs across CHRNA5/A3 associated with AD. Because these variants are in low linkage disequilibrium (LD) with the SNPs associated with $\mathrm{ND}$ and lung cancer, the authors concluded that CHRNA5/A3 variants are associated with $\mathrm{AD}$ but through different SNPs and mechanisms from those identified in ND and lung cancer. Moreover, Grucza et al. ${ }^{53}$ found that a nonsynonymous polymorphism in CHRNA5 has the opposite effect on cocaine dependence (CD) than is associated with ND. Such contradictions in allelic associations are found in other psychiatric disorders also. ${ }^{54}$ It remains to be seen whether there is true heterogeneity of association (in this case, between ND and CD), or whether some findings will turn out to be false positives.

\section{Future research on the CHRNA5/A3/B4 cluster}

Further steps are required to characterize the $C H R N A 5 / A 3 / B 4$ cluster as a susceptibility locus for addictions and lung cancer. First, it is important to determine which variant(s) cause such significant associations. Resequencing might identify additional variants that explain the complex patterns, but functional analysis also will be necessary. The nonsynomous variant rs16969968 (Asp398Asn) causes the substitution of a negatively charged residue within the M3-M4 intracellular loop of CHRNA3 (Box 2), a region thought to be involved with receptor trafficking. Indeed, the variant form of $C H R N A 5$ alters receptor function without affecting expression. ${ }^{55}$ Second, it is important to determine whether the $C H R N A 5 / A 3 / B 4$ cluster also has a significant role in non-European populations. Third, more research is needed to determine which smoking-related behavior drives the association with this cluster. For example, ND was measured by smoking quantity in two studies, ${ }^{48,50}$ whereas another focused on searching for susceptibility genes underlying the transition from regular non-dependent to dependent smokers. ${ }^{49}$ Weiss et al. ${ }^{51}$ found a significant association of the cluster with ND only in earlyonset smokers. Fourth, other genes in the region, such as a hypothetical locus LOC123688, cannot be excluded because of the association with other SNPs within this cluster. ${ }^{47}$ However, this issue may be difficult to solve genetically because of the extensive LD structure. 


\section{Associations of other genes with addictions}

Although many candidate genes have been associated with addiction (see Table 1 for verified and Supplementary Table 1 for non-verified genes associated with multiple substances and Supplementary Table 2 for genes associated with only one substance), few findings have been replicated. Given the controversial association reports for many genes, we focus on genes that have not only received strong statistical support for association with multiple substances of abuse but also have greater biological support.

Variants in GABRA2 are strongly associated with alcoholism, ${ }^{24-27}$ but an association has been reported between $G A B R A 2$ variants and addiction to nicotine and polysubstance abuse. ${ }^{56,57}$ Furthermore, a linkage study has implicated the region near GABRA2 in the etiology of cannabis use. ${ }^{58}$ Variants in $A N K K 1$, a protein kinase involved in signal transduction, ${ }^{59}$ have also been associated with susceptibility to $\mathrm{ND},{ }^{60,61} \mathrm{AD},{ }^{62,63}$ and comorbid alcohol and drug dependence. ${ }^{64}$ Finally, several GWASs provide evidence for the involvement of cell adhesionrelated genes in vulnerability to addiction and other psychiatric disorders. ${ }^{65}$ Representative members of this category include neurexin 1 for $\mathrm{ND}^{66,67}$ and neurexin 3 for polysubstance, 65 alcohol, ${ }^{68}$ and opioid abuse. ${ }^{69}$ Rare mutations in several members of this gene family, including neurexin 1 , also have been associated with autism ${ }^{54,70}$ and schizophrenia, ${ }^{71}$ implying the members of this family are important in many psychiatric disorders.

\section{Murine behavioral studies}

\section{Knockout (KO) models of nAChR subunit genes}

Genes encoding nAChRs mediate variability in many of the behavioral effects of nicotine. KO mice for nAChR subunits $\alpha 3-\alpha 9$ and $\beta 2-\beta 4$ have shown that the deletion of these genes alters many effects of nicotine. Unlike wild-type animals, mice lacking the $\alpha 4$ and $\beta 2$ subunits do not self-administer nicotine and do not show nicotine-induced increases of dopamine in the ventral stratum. ${ }^{72,73}$ In addition, $\beta 2 \mathrm{KO}$ mice self-administer cocaine but fail to maintain selfadministration when cocaine is switched to nicotine,${ }^{72}$ whereas $\alpha 4 \mathrm{KO}$ mice exhibit a prolonged motor response to cocaine. ${ }^{73}$ Together, the findings from $\alpha 4$ and $\beta 2 \mathrm{KO}$ mice provide evidence that $\alpha 4 \beta 2 *$ (* indicates another undetermined subunit) nAChRs are required for proper regulation of dopamine release and maintenance of self-administration and reinforcement.

KO mice of $\alpha 5^{74}$ and $\beta 4^{75}$, as well as $\alpha 3 \mathrm{KO}$ heterozygous mice, ${ }^{76}$ show that each of the three genes in a cluster on chromosome 15 mediates similar effects of nicotine; i.e., the animals show resistance to nicotine-induced seizures, whereas the $\alpha 5$ and $\alpha 3$ subunits mediate both the locomotion-suppressant effects of nicotine and somatic signs of nicotine withdrawal.

\section{Knockin (KI) model of $\alpha \mathbf{4}$ nAChR subunit in nicotine}

To better understand the roles of $\alpha 4$-containing nAChRs, a KI approach was adopted with the goal of making a hypersensitive nAChR that might generate more noticeable phenotypes. One of the most successful examples of this approach was the generation of two lines of $\alpha 4 \mathrm{KI}$ mice by introducing a point mutation into the M2 transmembrane region of the $\alpha 4$ subunit. ${ }^{77,78}$ In Leu9'Ser KI mice, this mutation produces $\alpha 4$-containing nAChRs with a $\sim 30$-fold increase in sensitivity to acetylcholine and nicotine. Heterozygous KI mice exhibit greater anxiety, impaired motor learning, excessive ambulation that is eliminated by small amounts of nicotine, and reduction of dopaminergic function on aging. ${ }^{78}$ In contrast, both homozygous and heterozygous Leu9'Ala KI mice are exceptionally sensitive to nicotine and ND-related behaviors, including reward, tolerance, and sensitization. ${ }^{77}$ These findings suggest that genetic variability in the $\alpha 4$ subunit can produce dramatic changes in nicotine sensitivity, implying that a variant(s) in the human CHRNA4 gene alters sensitivity to nicotine and vulnerability to ND. 


\section{Mouse models of GABA genes in alcohol and other addictions}

Rodent models of addiction have been studied for decades. ${ }^{79}$ QTL mapping of alcohol withdrawal identified several loci reproducibly: for example, one replicated locus involves nonsynonymous variants in GABRA2. ${ }^{80}$ Deletion of $\mathrm{GABA}_{\mathrm{A}}$ receptor $\alpha 1$ or $\beta 2$ subunits leads to reduced loss of the righting reflex in response to alcohol, as well as reduced consequences in response to other drugs. ${ }^{81}$ Conversely, sensitivity to alcohol can be manipulated by overexpression or reduction of the activity of the GABA transporter. ${ }^{82}$

Overall, many other mutants, $\mathrm{KI}, \mathrm{KO}$, and transgenic mice of various GABA subunit genes have convincingly established a role for GABA in mediating the behavioral consequences of alcohol ${ }^{79}$ and other drugs. ${ }^{83}$ The specific genes and alleles may differ from those associated in humans, but overall, animal models have confirmed and extended findings of GABA's involvement in $\mathrm{AD}$ and other addictions. ${ }^{79,83}$ The molecular mechanism of the effects of GABA are being established by microarray analysis. ${ }^{79,84}$

\section{Conclusions}

Significant progress has been made in identifying susceptibility loci and genes for addictions. Comparison of linkage peaks for addictions to various substances confirms what we have learned from genetic epidemiological studies, namely that genetic vulnerability to different substances in part overlaps. Variants in several genes, including aldehyde dehydrogenases, GABRA2, ANKK1, and neurexins 1 and 3, have been associated with addictions to multiple drugs. Most recently, variants of the CHRNA5/A3/B4 cluster on chromosome 15 were found by GWAS, as well as by targeted studies, to be associated not only with addictions to tobacco, alcohol, and cocaine, but with lung cancer as well. These genes have effects on nicotine responses in animal models and can thus be considered established targets for these studies. Nevertheless, the exact nature of the variants and their functions are still unknown. Functional studies as well as studies in other ethnic populations with different LD structure may be revealing. GWAS confirmation of candidate gene findings is reassuring, and similar to the robust findings in type II diabetes ${ }^{85}$ but in sharp contrast to GWAS results in other psychiatric disorders, which so far have failed to replicate any candidate findings. ${ }^{54}$ Such candidate genes with prior biochemical evidence and animal models allow a quicker move to functional studies. Well-designed GWASs with large samples should help to identify additional genes, including genes that implicate novel biological pathways involved in addiction.

\section{Box 1: Definition of addiction and challenges in addiction genetics research}

\section{Diagnostic assessment of addiction: nicotine dependence as an example}

Drug addiction is characterized by a compulsion to take a substance, with goal-directed behavior toward excessive substance intake and a loss of control in limiting intake. Clinical addictions generally are diagnosed using the Diagnostic and Statistical Manual IV (DSMIV) ${ }^{86}$ and the International Classification of Disease, $10^{\text {th }}$ Revision (ICD-10) of the World Health Organization (WHO) ${ }^{87}$ The most recent versions of DSM-IV and ICD-10 recognize two categorizes of addiction: abuse or harmful use, characterized by regular and increasing intake despite adverse consequences, and dependence, which in addition requires symptoms of withdrawal and/or tolerance.

Although there is significant comorbidity among addiction to different drugs, the measurement of various addictions differs greatly. Here, we use nicotine dependence (ND) to illustrate the complexity of this behavior. Historically, the assessment of ND has relied largely on the use of the Fagerström Tolerance Questionnaire ${ }^{88}$ or a shorter version, the FTND. ${ }^{89}$ Since they were introduced, these two scales have been used frequently in both clinical and research settings, partly because of their relation to treatment outcome. 
However, the Fagerström scales were developed as unidimensional measures of physical tolerance ${ }^{88}$ and thus do not assess some important aspects of ND, such as craving, subjective compulsion to smoke, nicotine withdrawal symptoms, BEHAVIORAL SALIENCY, Or BEHAVIORAL autoматісіту, which often are regarded as core constructs of ND. 90

ND also can be assessed by diagnostic criteria based on the DSM-IV. ${ }^{86}$ However, these symptoms are ultimately aggregated into a dichotomous classification as "dependent" or "not dependent," which limits its usefulness for research into the causes of addiction. Given that a diagnosis of dependence can be assigned by meeting various combinations of criteria, the diagnosis is conceptually heterogeneous. To expand the breadth of the diagnosis criteria and thereby improve the self-reported assessment of ND, new scales such as the Wisconsin Inventory of Smoking Dependence Motives ${ }^{91}$ and the Nicotine Dependence Syndrome Scale ${ }^{92}$ were developed. Whether these new scales can capture different aspects underlying ND and reduce the phenotypic heterogeneity among smokers remains to be investigated, especially in non-Caucasian smokers.

\section{Genetic and phenotypic heterogeneity}

One of the most significant challenges in genetic research on addiction concerns heterogeneity at both the phenotypic and genetic levels. Phenotypic heterogeneity is extensive in the manifestation of addiction, with users differing in magnitudes such as age of onset of problems, drug symptoms, abusing history, and comorbid disorders. One means to reduce phenotypic heterogeneity is to classify more genetically or neurobiological homogeneous phenotypes or use ENDOPHENOTYPEs as an intermediate phenotype between an addicted phenotype and the biological processes responsible for the manifestation of that disorder. GENETIC HETEROGENEITY is another major concern in genetic studies on addiction. Genetic differences exist between different ethnic groups or samples from different geographic locations. One way to minimize the impact on final genetics findings is to increase sample size and use more homogeneous samples.

\section{Box 2: Composition and function of neuronal nicotinic acetylcholine receptors (nAChRs) in the brain [contains figure]}

Neuronal nicotinic acetylcholine receptors belong to a super-family of ligand-gated ion channels that also includes receptors for GABA, glutamate, glycine, and serotonin. nAChRs are pentameric complexes assembled from an extensive family of subunits. In vertebrates, $12 \mathrm{nAChR}$ subunit genes with a common ancestor have been cloned and classified into two subfamilies of nine alpha $(\alpha 2-\alpha 10)$ and three beta subunits $(\beta 2-\beta 4)$. There is considerable subunit diversity amongst nAChR subtypes and, consequently, receptor subtypes are commonly referred to by their subunit composition.

nAChRs are widely distributed in the brain, and their subunit composition is cell and region specific. Most nAChRs in the nervous system contain one type of $\alpha$ and one type of $\beta$ subunit, with $\alpha 4 \beta 2$ receptors accounting for $90 \%$ of the high-affinity $\mathrm{nAChRs}$ in the brain; $\alpha 3 \beta 4$ receptors are the main subtype in the autonomic ganglia and adrenal medulla as well as in subsets of central nervous system neurons. The $\alpha 4 \beta 2$ and $\alpha 3 \beta 4$ subtypes also can contain the $\alpha 5$ subunit, which is believed to increase the rate of channel desensitization and calcium permeability.

Because nAChRs are the primary site of action for nicotine in the brain, they are important targets for the development of therapeutic agents that facilitate smoking cessation efforts. $\mathrm{nAChRs}$ are composed of five subunits that combine to form a functional receptor (Panel a). Each subunit comprises four membrane-spanning domains, which are arranged in concentric layers around a central aqueous pore with the M2 domain lining the pore. On $\mathrm{nAChR}$ activation by an endogenous agonist (acetylcholine, for example) or exogenous 
agonist (such as nicotine), the domains of each of the five $\mathrm{nAChR}$ subunits rearrange such that the central pore opens and permits cationic trafficking (Panel $\boldsymbol{b}$ ). Nicotine binds at the interface between the $\alpha$ and $\beta$ subunits in heteromeric nAChRs to activate the receptor (Panel c). Activation of nAChRs can potentiate neurotransmitter release (when expressed at presynaptic terminals) and neuronal excitability (when expressed at postsynaptic terminals) throughout the brain. As a result, $\mathrm{nAChRs}$ contribute to a wide range of brain activities that include cognitive functions and neuronal development and degeneration. Nicotine dependence is initiated through the activation of nAChRs. Chronic nicotine exposure produces the long-lasting physiological and behavioral changes associated with addiction, including $\mathrm{nAChR}$ up-regulation, gene expression alteration, and long-term potentiation and depression induction at glutamatergic synapses.

\section{Supplementary Material}

Refer to Web version on PubMed Central for supplementary material.

\section{Acknowledgments}

The authors are supported by grants from the National Institutes of Health (DA12844, DA-13783, DA15462S1, AA012217, and AA016104). The authors thank Chamindi Seneviratne, Ju Wang, and Jennie Z. Ma of the University of Virginia for assistance in the preparation of tables and figures.

\section{Short Biographies}

Ming D. Li is the Jean and Ronald Butcher Professor of Genetics in Psychiatry and Neuroscience and Head of the Section of Neurobiology in the Department of Psychiatry and Neurobehavioral Sciences at the University of Virginia in Charlottesville. Dr Li received his MS in statistical genetics and PhD in molecular genetics/biology at the University of Minnesota in Minneapolis. After carrying out postdoctoral research in genetics and neuropharmacology, he has served on the faculties of three institutions. Dr Li's research focuses on the identification and characterization of genes underlying drug addiction in both humans and animals, with a focus on nicotine dependence, using genomics, functional genomics, and bioinformatics approaches.

Margit Burmeister received a Diplom (M.S.) in biochemistry from the Free University of Berlin, Germany with thesis work at the Weizmann Institute of Science in Rehovot, Israel and a Dr. rer. nat. (a Ph.D. equivalent) in biology from the Ruprecht-Karls University in Heidelberg, Germany, for work performed with Hans Lehrach at the European Molecular Biology Laboratory. After carrying out postdoctoral research at the University of California in San Francisco, with Richard M. Myers and David R. Cox, she joined the faculty of the Molecular \& Behavioral Neuroscience Institute and Departments of Psychiatry and Human Genetics at the University of Michigan, where she now also serves as the Director of the Bioinformatics Graduate Program in the Center for Computational Medicine and Bioinformatics.

\section{Glossary}

Behavioral
automaticity

Behavioral saliency

Depression Induction
Control of behavior by external stimuli and events in the immediate environment, often without knowledge or awareness of such control.

In the context of this article, the likelihood and the degree to which a stimulus elicits a reaction or response.

A procedure that induces a state of depression. 
Endophenotype

Generalized

Multifactor

Dimensionality

Reduction (GMDR)

method

Genetic Heterogeneity

Haplotype

Heritability

Linkage Mapping

Long-term

potentiation

Multifactor

dimensionality

reduction method

(MDR)

Positional Candidate

Gene Approach

Quantitative Trait

Locus (QTL) mapping

Tagging SNPs
In psychiatry, a biomarker for a behavioral symptom that has a clear genetic connection.

An extension of MDR applicable to different kinds of phenotypes that allows covariate adjustment on the basis of generalized linear models.

Causation of a disorder or trait by different genetic variants in different samples. This can arise when participants of different ethnic origins are included, genetic effects or samples are small, and marker density is low.

A combination of the alleles at different loci on the same chromosome.

The proportion of phenotypic variance that can be attributed to variance of the genotype.

Linkage refers to the tendency of two close loci on the same chromosome to co-segregate within a pedigree. Genome-wide linkage scanning can identify loci involved in conditions for which there is no a priori reason to suspect any contribution.

The long-lasting improvement in communication between two neurons that results from stimulating them simultaneously.

A data reduction approach for detecting combinations of attributes or independent variables that interact to influence a binary outcome.

A candidate gene-based association study following a genome region identified from linkage analysis.

The statistical study of the genetic loci that contribute to variations in a quantitative trait or phenotype.

An informative subset of SNPs that can explain the majority of the complex patterns of linkage disequilibrium between adjacent SNPs in a region of interest.

\section{References}

1. Kreek MJ, Nielsen DA, Butelman ER, LaForge KS. Genetic influences on impulsivity, risk taking, stress responsivity and vulnerability to drug abuse and addiction. Nat Neurosci 2005;8:1450-1457. [PubMed: 16251987]

2. Edenberg HJ, Foroud T. The genetics of alcoholism: identifying specific genes through family studies. Addict Biol 2006;11:386-396. [PubMed: 16961766]

3. Goldman D, Oroszi G, Ducci F. The genetics of addictions: uncovering the genes. Nat Rev Genet 2005;6:521-532. [PubMed: 15995696]

4. Li MD, Cheng R, Ma JZ, Swan GE. A meta-analysis of estimated genetic and environmental effects on smoking behavior in male and female adult twins. Addiction 2003;98:23-31. [PubMed: 12492752]

5. Uhl GR, Liu QR, Naiman D. Substance abuse vulnerability loci: converging genome scanning data. Trends Genet 2002;18:420-425. [PubMed: 12142011] 
6. Lee AM, et al. CYP2B6 genotype alters abstinence rates in a bupropion smoking cessation trial. Biol Psychiatry 2007;62:635-641. [PubMed: 17223085]

7. Li MD. Identifying susceptibility loci for nicotine dependence: 2008 update based on recent genomewide linkage analyses. Hum Genet 2008;123:119-131. [PubMed: 18205015]

8. Agrawal A, Lynskey MT. Are there genetic influences on addiction: evidence from family, adoption and twin studies. Addiction 2008;103:1069-1081. [PubMed: 18494843]

9. Madden PA, et al. The genetics of smoking persistence in men and women: a multicultural study. Behav Genet 1999;29:423-431. [PubMed: 10857247]

10. Tsuang MT, et al. Genetic influences on DSM-III-R drug abuse and dependence: a study of 3,372 twin pairs. Am J Med Genet 1996;67:473-477. [PubMed: 8886164]

11. Kendler KS, Prescott CA. Cocaine use, abuse and dependence in a population-based sample of female twins. Br J Psychiatry 1998;173:345-350. [PubMed: 9926041]

12. True WR, et al. Common genetic vulnerability for nicotine and alcohol dependence in men. Arch Gen Psychiatry 1999;56:655-661. [PubMed: 10401514]

13. Long JC, et al. Evidence for genetic linkage to alcohol dependence on chromosomes 4 and 11 from an autosome-wide scan in an American Indian population. Am J Med Genet 1998;81:216-221. [PubMed: 9603607]

14. Reich T, et al. Genome-wide search for genes affecting the risk for alcohol dependence. Am J Med Genet 1998;81:207-215. [PubMed: 9603606]

15. Saccone NL, et al. A genome screen of maximum number of drinks as an alcoholism phenotype. Am J Med Genet 2000;96:632-637. [PubMed: 11054770]

16. Osier MV, et al. A global perspective on genetic variation at the ADH genes reveals unusual patterns of linkage disequilibrium and diversity. Am J Hum Genet 2002;71:84-99. [PubMed: 12050823]

17. Shea SH, Wall TL, Carr LG, Li TK. ADH2 and alcohol-related phenotypes in Ashkenazic Jewish American college students. Behav Genet 2001;31:231-239. [PubMed: 11545539]

18. Higuchi S, Muramatsu T, Matsushita S, Murayama M, Hayashida M. Polymorphisms of ethanoloxidizing enzymes in alcoholics with inactive ALDH2. Hum Genet 1996;97:431-434. [PubMed: 8834237]

19. Osier M, et al. Linkage disequilibrium at the ADH2 and ADH3 loci and risk of alcoholism. Am J Hum Genet 1999;64:1147-1157. [PubMed: 10090900]

20. Edenberg HJ, et al. Association of alcohol dehydrogenase genes with alcohol dependence: a comprehensive analysis. Hum Mol Genet 2006;15:1539-1549. [PubMed: 16571603]

21. Osier MV, et al. Possible epistatic role of ADH7 in the protection against alcoholism. Am J Med Genet B Neuropsychiatr Genet 2004;126B:19-22. [PubMed: 15048643]

22. Zinn-Justin A, Abel L. Genome search for alcohol dependence using the weighted pairwise correlation linkage method: interesting findings on chromosome 4. Genet Epidemiol 1999;17(Suppl 1):S421426. [PubMed: 10597473]

23. Porjesz B, et al. Linkage and linkage disequilibrium mapping of ERP and EEG phenotypes. Biol Psychol 2002;61:229-248. [PubMed: 12385677]

24. Edenberg HJ, et al. Variations in GABRA2, encoding the alpha 2 subunit of the GABA(A) receptor, are associated with alcohol dependence and with brain oscillations. Am J Hum Genet 2004;74:705714. [PubMed: 15024690]

25. Covault J, Gelernter J, Hesselbrock V, Nellissery M, Kranzler HR. Allelic and haplotypic association of GABRA2 with alcohol dependence. Am J Med Genet B Neuropsychiatr Genet 2004;129:104109. [PubMed: 15274050]

26. Lappalainen J, et al. Association between alcoholism and gamma-amino butyric acid alpha2 receptor subtype in a Russian population. Alcohol Clin Exp Res 2005;29:493-498. [PubMed: 15834213]

27. Fehr C, et al. Confirmation of association of the GABRA2 gene with alcohol dependence by subtypespecific analysis. Psychiatr Genet 2006;16:9-17. [PubMed: 16395124]

28. Beuten J, et al. Single- and Multilocus Allelic Variants within the GABAB Receptor Subunit 2 (GABAB2) Gene Are Significantly Associated with Nicotine Dependence. Am. J. Hum. Genet 2005;76:859-864. [PubMed: 15759211] 
29. Bergen AW, Korczak JF, Weissbecker KA, Goldstein AM. A genome-wide search for loci contributing to smoking and alcoholism. Genet Epidemiol 1999;17(Suppl 1):S55-60. [PubMed: 10597412]

30. Li MD, et al. A genome-wide scan to identify loci for smoking rate in the Framingham Heart Study population. BMC Genet 2003;4(Suppl 1):S103. [PubMed: 14975171]

31. Bierut LJ, et al. A genomic scan for habitual smoking in families of alcoholics: common and specific genetic factors in substance dependence. Am J Med Genet 2004;124A:19-27. [PubMed: 14679582]

32. Gelernter J, et al. Results of a genomewide linkage scan: support for chromosomes 9 and 11 loci increasing risk for cigarette smoking. Am J Med Genet 2004;128B:94-101. [PubMed: 15211640]

33. Li MD. The genetics of nicotine dependence. Curr Psychiatry Rep 2006;8:158-164. [PubMed: 16539894]

34. Lander E, Kruglyak L. Genetic dissection of complex traits: guidelines for interpreting and reporting linkage results. Nat Genet 1995;11:241-247. [PubMed: 7581446]

35. Feng Y, et al. A common haplotype of the nicotine acetylcholine receptor alpha 4 subunit gene is associated with vulnerability to nicotine addiction in men. Am J Hum Genet 2004;75:112-121. [PubMed: 15154117]

36. Li MD, et al. Ethnic- and gender-specific association of the nicotinic acetylcholine receptor alpha4 subunit gene (CHRNA4) with nicotine dependence. Hum Mol Genet 2005;14:1211-1219. [PubMed: 15790597]

37. Hutchison KE, et al. CHRNA4 and tobacco dependence: from gene regulation to treatment outcome. Arch Gen Psychiatry 2007;64:1078-1086. [PubMed: 17768273]

38. Conti DV, et al. Nicotinic acetylcholine receptor beta2 subunit gene implicated in a systems-based candidate gene study of smoking cessation. Hum Mol Genet 2008;17:2834-2848. [PubMed: 18593715]

39. Lou XY, et al. A Generalized Combinatorial Approach for Detecting Gene-by-Gene and Gene-byEnvironment Interactions with Application to Nicotine Dependence. Am J Hum Genet 2007;80:1125-1137. [PubMed: 17503330]

40. Li MD, Lou XY, Chen G, Ma JZ, Elston RC. Gene-gene interactions among CHRNA4, CHRNB2, BDNF, and NTRK2 in nicotine dependence. Biol Psychiatry 2008;64:951-957. [PubMed: 18534558]

41. Marubio LM, et al. Reduced antinociception in mice lacking neuronal nicotinic receptor subunits. Nature 1999;398:805-810. [PubMed: 10235262]

42. Picciotto MR, et al. Abnormal avoidance learning in mice lacking functional high-affinity nicotine receptor in the brain. Nature 1995;374:65-67. [PubMed: 7870173]

43. Ehringer MA, et al. Association of the neuronal nicotinic receptor beta2 subunit gene (CHRNB2) with subjective responses to alcohol and nicotine. Am J Med Genet B Neuropsychiatr Genet 2007;144B:596-604. [PubMed: 17226798]

44. Hatsukami DK, Stead LF, Gupta PC. Tobacco addiction. Lancet 2008;371:2027-2038. [PubMed: 18555914]

45. Steensland P, Simms JA, Holgate J, Richards JK, Bartlett SE. Varenicline, an alpha4beta2 nicotinic acetylcholine receptor partial agonist, selectively decreases ethanol consumption and seeking. Proc Natl Acad Sci U S A 2007;104:12518-12523. [PubMed: 17626178]

46. Amos CI, et al. Genome-wide association scan of tag SNPs identifies a susceptibility locus for lung cancer at 15q25.1. Nat Genet 2008;40:616-622. [PubMed: 18385676]

47. Hung RJ, et al. A susceptibility locus for lung cancer maps to nicotinic acetylcholine receptor subunit genes on 15q25. Nature 2008;452:633-637. [PubMed: 18385738]

48. Thorgeirsson TE, et al. A variant associated with nicotine dependence, lung cancer and peripheral arterial disease. Nature 2008;452:638-642. [PubMed: 18385739]

49. Saccone SF, et al. Cholinergic nicotinic receptor genes implicated in a nicotine dependence association study targeting 348 candidate genes with 3713 SNPs. Hum Mol Genet 2007;16:36-49. [PubMed: 17135278]

50. Berrettini W, et al. Alpha-5/alpha-3 nicotinic receptor subunit alleles increase risk for heavy smoking. Mol Psychiatry 2008;13:368-373. [PubMed: 18227835] 
51. Weiss RB, et al. A candidate gene approach identifies the CHRNA5-A3-B4 region as a risk factor for age-dependent nicotine addiction. PLoS Genet 2008;4:e1000125. [PubMed: 18618000]

52. Wang JC, et al. Genetic variation in the CHRNA5 gene affects mRNA levels and is associated with risk for alcohol dependence. Mol Psychiatry. April 15;2008 doi:10.1038/mp.2008.42.

53. Grucza RA, et al. A risk allele for nicotine dependence in CHRNA5 is a protective allele for cocaine dependence. Biol Psychiatry 2008;64:922-929. [PubMed: 18519132]

54. Burmeister M, McInnis MG, Zollner S. Psychiatric genetics: progress amid controversy. Nat Rev Genet 2008;9:527-540. [PubMed: 18560438]

55. Bierut LJ, et al. Variants in Nicotinic Receptors and Risk for Nicotine Dependence. Am J Psychiatry 2008;165:1163-1171. [PubMed: 18519524]

56. Agrawal A, et al. Gamma-aminobutyric acid receptor genes and nicotine dependence: evidence for association from a case-control study. Addiction 2008;103:1027-1038. [PubMed: 18482426]

57. Drgon T, D'Addario C, Uhl GR. Linkage disequilibrium, haplotype and association studies of a chromosome $4 \mathrm{GABA}$ receptor gene cluster: candidate gene variants for addictions. Am J Med Genet B Neuropsychiatr Genet 2006;141B:854-860. [PubMed: 16894595]

58. Agrawal A, et al. An autosomal linkage scan for cannabis use disorders in the nicotine addiction genetics project. Arch Gen Psychiatry 2008;65:713-721. [PubMed: 18519829]

59. Neville MJ, Johnstone EC, Walton RT. Identification and characterization of ANKK1: a novel kinase gene closely linked to DRD2 on chromosome band 11q23.1. Hum Mutat 2004;23:540-545. [PubMed: 15146457]

60. Gelernter J, et al. Haplotype spanning TTC12 and ANKK1, flanked by the DRD2 and NCAM1 loci, is strongly associated to nicotine dependence in two distinct American populations. Hum Mol Genet 2006;15:3498-3507. [PubMed: 17085484]

61. Huang W, et al. Significant association of ANKK1 and detection of a functional polymorphism with nicotine dependence in an African-American sample. Neuropsychopharmacology 2009;34:319-330. [PubMed: 18354387]

62. Dick DM, et al. Family-based association analyses of alcohol dependence phenotypes across DRD2 and neighboring gene ANKK1. Alcohol Clin Exp Res 2007;31:1645-1653. [PubMed: 17850642]

63. Yang BZ, et al. Association of haplotypic variants in DRD2, ANKK1, TTC12 and NCAM1 to alcohol dependence in independent case control and family samples. Hum Mol Genet 2007;16:2844-2853. [PubMed: 17761687]

64. Yang BZ, et al. Haplotypic variants in DRD2, ANKK1, TTC12, and NCAM1 are associated with comorbid alcohol and drug dependence. Alcohol Clin Exp Res 2008;32:2117-2127. [PubMed: 18828801]

65. Uhl GR, et al. Molecular genetics of addiction and related heritable phenotypes: genome-wide association approaches identify "connectivity constellation" and drug target genes with pleiotropic effects. Ann N Y Acad Sci 2008;1141:318-381. [PubMed: 18991966]

66. Nussbaum J, et al. Significant association of the neurexin-1 gene (NRXN1) with nicotine dependence in European- and African-American smokers. Hum Mol Genet 2008;17:1569-1577. [PubMed: 18270208]

67. Bierut LJ, et al. Novel genes identified in a high-density genome wide association study for nicotine dependence. Hum Mol Genet 2007;16:24-35. [PubMed: 17158188]

68. Hishimoto A, et al. Neurexin 3 polymorphisms are associated with alcohol dependence and altered expression of specific isoforms. Hum Mol Genet 2007;16:2880-2891. [PubMed: 17804423]

69. Lachman HM, et al. Genomewide suggestive linkage of opioid dependence to chromosome 14q. Hum Mol Genet 2007;16:1327-1334. [PubMed: 17409192]

70. Kim HG, et al. Disruption of neurexin 1 associated with autism spectrum disorder. Am J Hum Genet 2008;82:199-207. [PubMed: 18179900]

71. Rujescu D, et al. Disruption of the neurexin 1 gene is associated with schizophrenia. Hum Mol Genet. October 22;2008

72. Picciotto MR, et al. Acetylcholine receptors containing the beta2 subunit are involved in the reinforcing properties of nicotine. Nature 1998;391:173-177. [PubMed: 9428762] 
73. Marubio LM, et al. Effects of nicotine in the dopaminergic system of mice lacking the alpha4 subunit of neuronal nicotinic acetylcholine receptors. Eur J Neurosci 2003;17:1329-1337. [PubMed: 12713636]

74. Salas R, et al. The nicotinic acetylcholine receptor subunit alpha 5 mediates short-term effects of nicotine in vivo. Mol Pharmacol 2003;63:1059-1066. [PubMed: 12695534]

75. Salas R, Pieri F, De Biasi M. Decreased signs of nicotine withdrawal in mice null for the beta4 nicotinic acetylcholine receptor subunit. J Neurosci 2004;24:10035-10039. [PubMed: 15537871]

76. Salas R, Cook KD, Bassetto L, De Biasi M. The alpha3 and beta4 nicotinic acetylcholine receptor subunits are necessary for nicotine-induced seizures and hypolocomotion in mice. Neuropharmacology 2004;47:401-407. [PubMed: 15275829]

77. Tapper AR, et al. Nicotine activation of alpha4* receptors: sufficient for reward, tolerance, and sensitization. Science 2004;306:1029-1032. [PubMed: 15528443]

78. Labarca C, et al. Point mutant mice with hypersensitive alpha 4 nicotinic receptors show dopaminergic deficits and increased anxiety. Proc Natl Acad Sci U S A 2001;98:2786-2791. [PubMed: 11226318]

79. Crabbe JC. Review. Neurogenetic studies of alcohol addiction. Philos Trans R Soc Lond B Biol Sci 2008;363:3201-3211. [PubMed: 18640917]

80. Buck KJ, Hood HM. Genetic association of a GABA(A) receptor gamma2 subunit variant with severity of acute physiological dependence on alcohol. Mamm Genome 1998;9:975-978. [PubMed: 9880662]

81. Blednov YA, et al. Deletion of the alpha1 or beta2 subunit of GABAA receptors reduces actions of alcohol and other drugs. J Pharmacol Exp Ther 2003;304:30-36. [PubMed: 12490572]

82. $\mathrm{Hu} \mathrm{JH}$, et al. Up-regulation of gamma-aminobutyric acid transporter I mediates ethanol sensitivity in mice. Neuroscience 2004;123:807-812. [PubMed: 14751274]

83. Buck KJ, Finn DA. Genetic factors in addiction: QTL mapping and candidate gene studies implicate GABAergic genes in alcohol and barbiturate withdrawal in mice. Addiction 2001;96:139-149. [PubMed: 11177525]

84. Ponomarev I, et al. Transcriptional signatures of cellular plasticity in mice lacking the alpha1 subunit of GABAA receptors. J Neurosci 2006;26:5673-5683. [PubMed: 16723524]

85. Scott LJ, et al. A genome-wide association study of type 2 diabetes in Finns detects multiple susceptibility variants. Science 2007;316:1341-1345. [PubMed: 17463248]

86. APA. American Psychiatric Association. Diagnostic and Statistical Manual of Mental Disorders. American Psychiatric Association; Washington DC: 1994.

87. WHO. International classification of disease (ICD-10). World Health Organization; Geneva: 1991.

88. Fagerstrom KO. Measuring degree of physical dependence to tobacco smoking with reference to individualization of treatment. Addict Behav 1978;3:235-241. [PubMed: 735910]

89. Heatherton TF, Kozlowski LT, Frecker RC, Fagerstrom KO. The Fagerstrom Test for Nicotine Dependence: a revision of the Fagerstrom Tolerance Questionnaire. Br. J. Addict 1991;86:11191127. [PubMed: 1932883]

90. Shadel WG, Shiffman S, Niaura R, Nichter M, Abrams DB. Current models of nicotine dependence: what is known and what is needed to advance understanding of tobacco etiology among youth. Drug Alcohol Depend 2000;59(Suppl 1):S9-22. [PubMed: 10773435]

91. Piper ME, et al. A multiple motives approach to tobacco dependence: the Wisconsin Inventory of Smoking Dependence Motives (WISDM-68). J Consult Clin Psychol 2004;72:139-154. [PubMed: 15065950]

92. Shiffman S, Waters A, Hickcox M. The nicotine dependence syndrome scale: a multidimensional measure of nicotine dependence. Nicotine Tob Res 2004;6:327-348. [PubMed: 15203807]

93. Feinn R, Nellissery M, Kranzler HR. Meta-analysis of the association of a functional serotonin transporter promoter polymorphism with alcohol dependence. Am J Med Genet B Neuropsychiatr Genet 2005;133B:79-84. [PubMed: 15635638]

94. Munafo MR, Clark TG, Johnstone EC, Murphy FG, Walton RT. The genetics basis for smoking behavior: A systematic review and meta-analysis. Nicotine Tob Res 2004;6:583-597. [PubMed: 15370155] 
95. Stapleton JA, Sutherland G, O'Gara C. Association between dopamine transporter genotypes and smoking cessation: a meta-analysis. Addict Biol 2007;12:221-226. [PubMed: 17508996]

96. Munafo MR, Matheson IJ, Flint J. Association of the DRD2 gene Taq1A polymorphism and alcoholism: a meta-analysis of case-control studies and evidence of publication bias. Mol Psychiatry 2007;12:454-461. [PubMed: 17453061]

97. Smith L, Watson M, Gates S, Ball D, Foxcroft D. Meta-analysis of the association of the Taq1A polymorphism with the risk of alcohol dependency: a HuGE gene-disease association review. Am J Epidemiol 2008;167:125-138. [PubMed: 17989061]

98. Foll BL, Gallo A, Le Strat Y, Lu L, Gorwood P. Genetics of dopamine receptors and drug addiction: a comprehensive review. Behav Pharmacol 2009;20:1-17. [PubMed: 19179847]

99. Li MD, Ma JZ, Beuten J. Progress in searching for susceptibility loci and genes for smoking-related behaviour. Clin. Genet 2004;66:382-392. [PubMed: 15479180]

100. Marcos M, Pastor I, Gonzalez-Sarmiento R, Laso FJ. Interleukin-10 gene polymorphism is associated with alcoholism but not with alcoholic liver disease. Alcohol Alcohol 2008;43:523-528. [PubMed: 18436572]

101. Gratacos M, et al. Brain-derived neurotrophic factor Val66Met and psychiatric disorders: metaanalysis of case-control studies confirm association to substance-related disorders, eating disorders, and schizophrenia. Biol Psychiatry 2007;61:911-922. [PubMed: 17217930] 


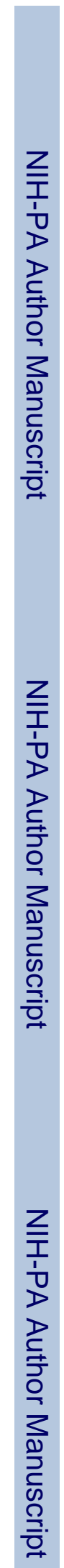

Page 15
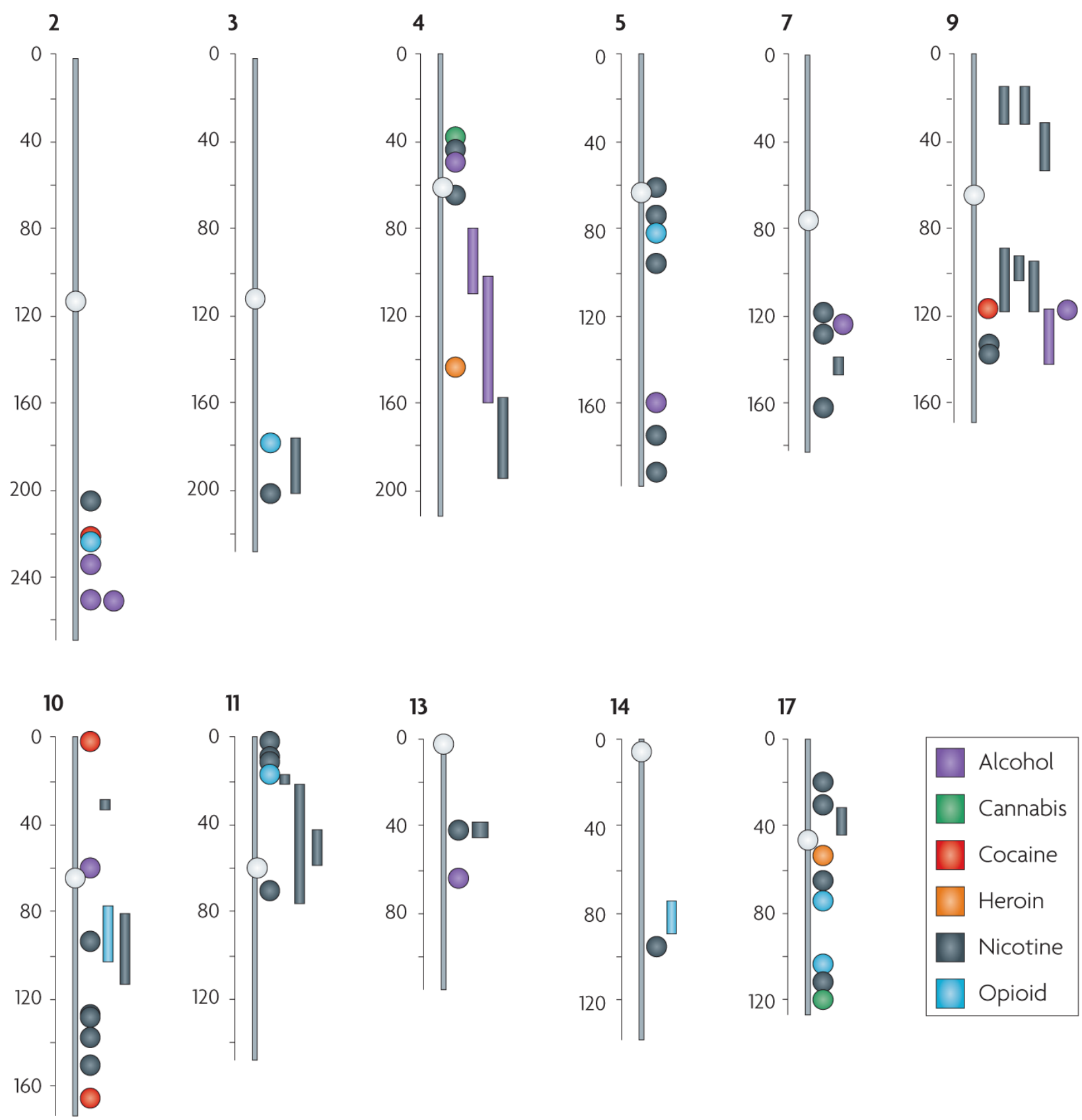

Nat Rev Genet. Author manuscript; available in PMC 2010 June 2. 

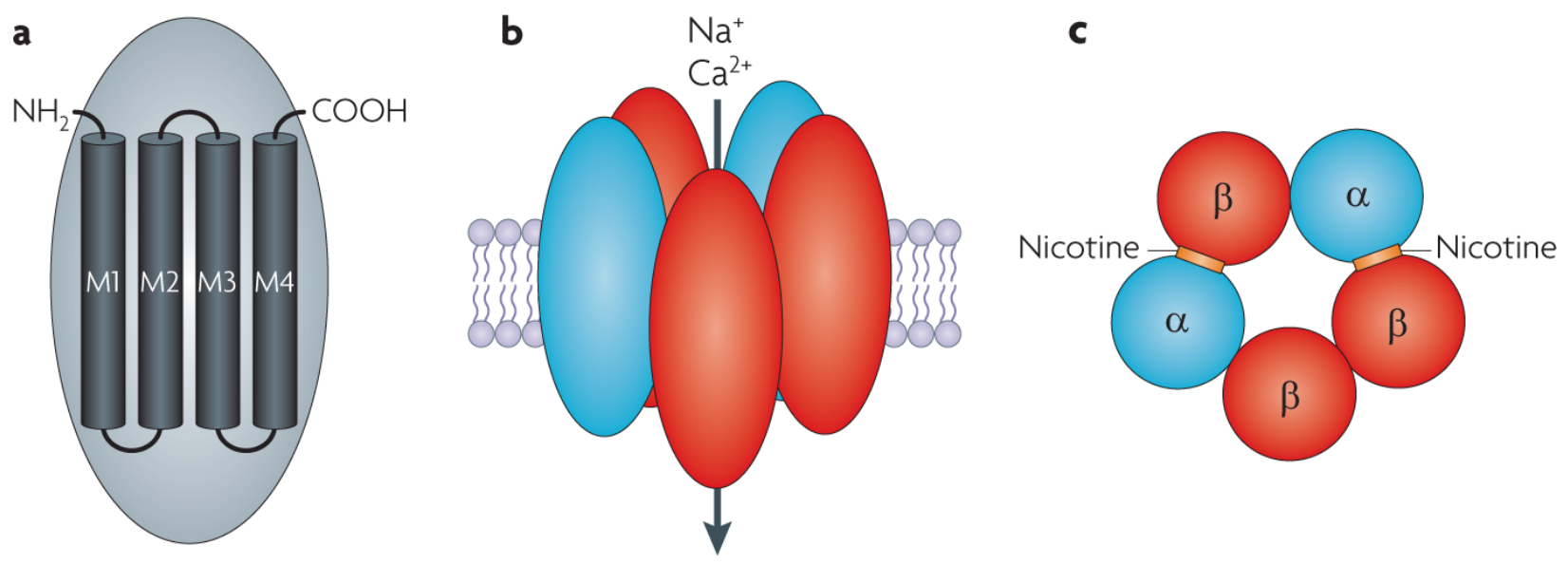

Figure 1. Chromosomal locations of peaks or intervals for addiction to multiple substances Summary of chromosomal locations of nominated peaks or intervals for addictions to alcohol, cannabis, cocaine, heroin, nicotine, and opoids. Each linkage is given with either a color-filled circle or a rectangle, representing a reported linkage peak or region, respectively. "Significant" or "suggestive" linkage was determined by independent studies on at least two substances of abuse. The determination of "significant" or "suggestive linkage" at each linkage peak/interval was based on the rigorous criteria proposed by Lander and Kruglyak, ${ }^{34}$ which define an LOD of $>3.6$ or a $\mathrm{P}$ value of $<2.2 \times 10^{-5}$ as a "significant linkage" and an LOD of $>2.2$ but $<3.6$ or a $\mathrm{P}$ value of $7.4 \times 10^{-4}$ as a "suggestive linkage." Each color represents a type of abused substance. The "unit" for each chromosome is "cM." 


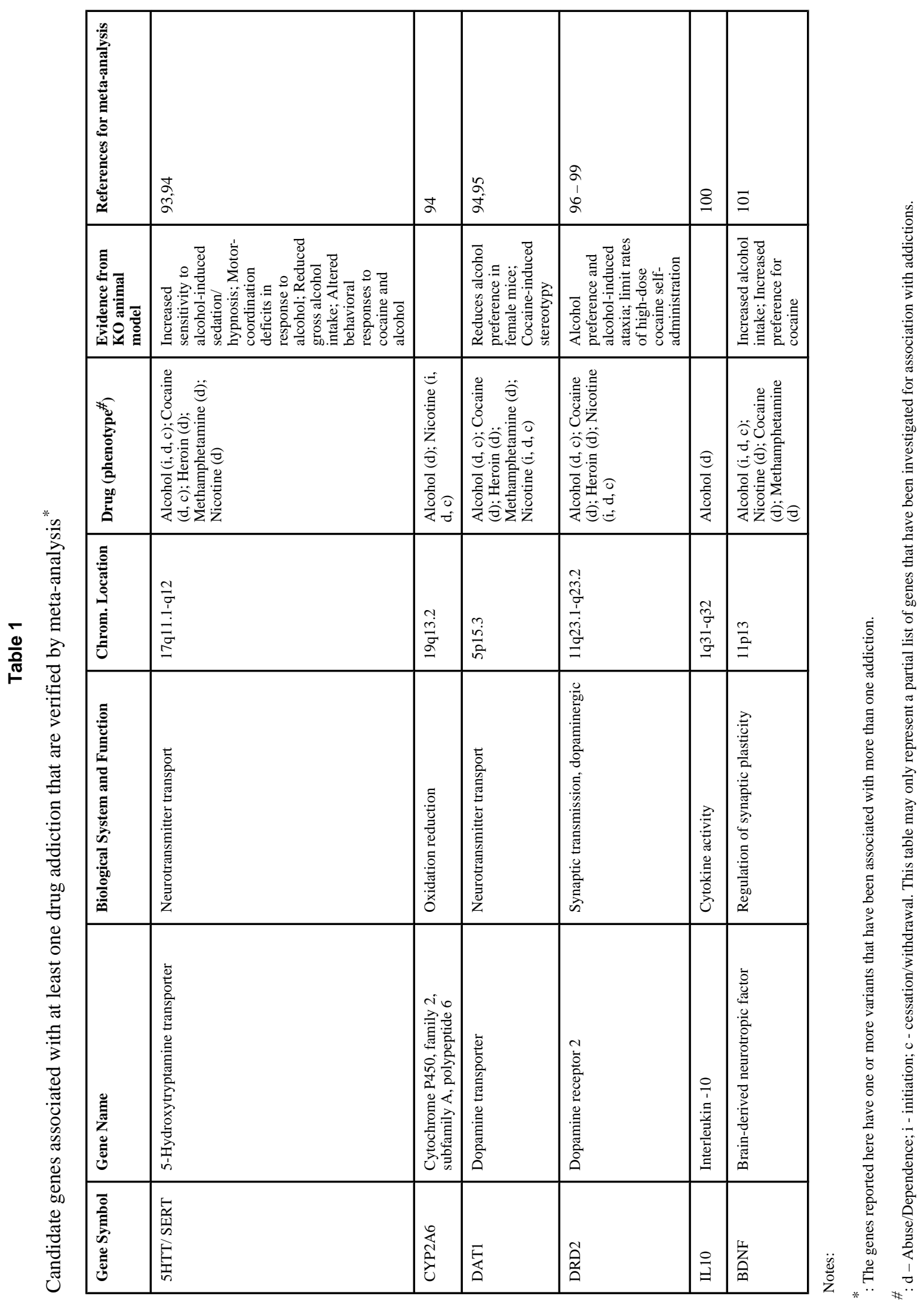

Nat Rev Genet. Author manuscript; available in PMC 2010 June 2. 